This document is the accepted manuscript version of the following article:

Li, J., Wan, W., Triana, C. A., Novotny, Z., Osterwalder, J., Erni, R., \& Patzke, G. R. (2019). Dynamic role of cluster cocatalysts on molecular photoanodes for water oxidation. Journal of the American Chemical Society, 141(32), 12839-12848.

https://doi .org/10.1021/jacs.9b06100

\title{
Dynamic Role of Cluster Cocatalysts on Molecular Photoanodes for Water Oxidation
}

\author{
Jingguo Li, ${ }^{1}$ Wenchao Wan, ${ }^{1}$ C. A. Triana, ${ }^{1}$ Zbynek Novotny, ${ }^{2}$ Jürg Osterwalder, ${ }^{2}$ \\ Rolf Erni, 3 Greta R. Patzke ${ }^{*_{1}}$
}

${ }^{1}$ Department of Chemistry, University of Zurich, Winterthurerstrasse 190, CH-8057 Zurich, Switzerland.

${ }^{2}$ Department of Physics, University of Zurich, Winterthurerstrasse 190, CH-8057 Zurich, Switzerland.

3Electron Microscopy Center, Empa, Swiss Federal Laboratories for Materials Science and Technology, CH-86oo Dübendorf, Switzerland

Keywords: Photoelectrochemical water oxidation, molecular devices, hybrid photoanodes, cocatalysts, artificial photosynthesis

\begin{abstract}
While loading of cocatalysts is one of the most widely investigated strategies to promote the efficiency of photoelectrodes, the understanding of their functionality remains controversial. We established new hybrid molecular photoanodes with cobalt-based molecular cubane cocatalysts on hematite as a model system. Photoelectrochemical and rate law analyses revealed an interesting functionality transition of the $\left\{\mathrm{Co}(\mathrm{II})_{4} \mathrm{O}_{4}\right\}$-type cocatalysts. Their role changed from predominantly hole reservoirs to catalytic centers upon modulation of the applied bias. Kinetic analysis of the photoelectrochemical processes indicated that this observed transition arises from the dynamic equilibria of photo-generated surface charge carriers. Most importantly, we confirmed this functional transition of the cocatalysts and the related kinetic properties for several cobalt-based molecular and heterogeneous catalysts, indicating wide applicability of the derived trends. Additionally, complementary analytical characterizations show that a transformation of the applied molecular species occurs at higher applied bias, pointing to a dynamic interplay connecting molecular and heterogeneous catalysis. Our insights promote the essential understanding of efficient (molecular) cocatalyzed photoelectrode systems to design tailor-made hybrid devices for a wide range of catalytic applications.
\end{abstract}

\section{Introduction}

Photoelectrochemical water splitting offers a promising route for direct solar energy-to-fuel conversion..$^{1-3}$ To date, the development of efficient photoanodes remains challenging due to the thermodynamically sluggish four-electron-transfer process involved in the oxygen evolution reaction (OER)..$^{-7}$ Cocatalyst loading has emerged as one of the most important approaches for eliminating OER overpotential losses with most emphasis placed on heterogeneous systems to date. However, the actual functionalities of such cocatalysts are still widely debated, because their understanding is essential for future efficient photoanode design. ${ }^{8}$ In contrast, the remarkable tuning options of molecular catalysts for water splitting with hybrid photoelectrodes have only been explored since 2010. ${ }^{9}$ As the interest in hybrid molecular photoanodes is just rising, ${ }^{10-14}$ less than ten studies on hybrid photoanodes for water splitting with noble metal-free molecular cocatalysts had been reported until 2017. ${ }^{9}$
We here comprehensively investigate the functionalities of molecular cocatalysts on photoanodes for the first time. Such studies are now vital to open up the unlimited variability of molecular building blocks for enhancing the performance of semiconductor electrodes. ${ }^{12,15}$ We present insight leading to an overarching concept that correlates previous diverse assignments of cocatalyst roles. ${ }^{16,17}$ Thereby, we bridge and compare the fields of molecular and heterogeneous cocatalysts.

Manifold techniques have been applied in preceding studies to clarify the role of heterogeneous cocatalysts, with special emphasis on cocatalyst-modified hematite photoanodes. ${ }^{18,19}$ In a key study, similar transient absorption spectroscopy (TAS) properties were observed on biased hematite photoanodes and on unbiased electrodes modified with $\mathrm{CoPi}$. These results suggested that $\mathrm{CoPi}$ cocatalysts could increase the band bending of the hematite photoanode through the formation of heterojunctions. ${ }^{20}$ This also applies for $\mathrm{CoO}_{x}$ as cocatalysts on hematite photoanodes, because such modified photoanodes required 
less anodic bias for the slow decay features in TAS. ${ }^{21}$ On the other hand, (photo)electrochemical techniques such as photoelectrochemical impedance spectroscopy (PEIS), ${ }^{22}$ transient photocurrent spectroscopy (TPS), ${ }^{23}$ double working electrode (DWE), ${ }^{24,25}$ and intensity modulated photocurrent spectroscopy (IMPS), ${ }^{26-28}$ have been employed as attractive options for probing the functionality of cocatalysts. In a representative study, CoPi loaded on hematite photoanodes was identified as a hole collector with the help of steady-state current density, TPS and PEIS analyses. ${ }^{29}$ In the course of a follow-up study, a similar hole storage function was observed for mixed $\mathrm{Ni}_{0.25} \mathrm{Fe}_{0.75} \mathrm{O}_{\mathrm{y}}$ oxides as cocatalysts on hematite. ${ }^{30}$ Kinetic studies using IMPS on a $\mathrm{NiFeO}_{x}$ modified hematite photoanode indicated a slowdown of both charge transfer and recombination kinetics, so that a surface passivation function was proposed for the cocatalysts. ${ }^{26}$ However, in a separate study using the DWE technique, a bi-functional role encompassing hole storage and catalytic activity was demonstrated for $\mathrm{Ni}_{0.8} \mathrm{Fe}_{0.2} \mathrm{O}_{\mathrm{x} .}{ }^{1{ }^{1}}$

Interestingly, the selected investigation technique seems to significantly influence the conclusions on the cocatalyst functionality. Given the underlying differences in working principles and conditions, ${ }^{18}$ this does not come unexpected. For example, TAS probes photo-generated hole decay kinetics after a very short period of laser illumination, while PEIS data are obtained under constant illumination. Furthermore, the different assignments of cocatalyst functionalities also highlight the complexity of the associated processes and the dependency of the results on the context of operational conditions. For example, ultrafast TAS measurements on bare hematite indicate that more than $50 \%$ of the photogenerated charge carriers would recombine within 6 ps without bias and over $98 \%$ in less than $6 \mu$ s at $1.43 \mathrm{~V}$ vs. RHE. ${ }^{32,33}$ This means that only a very small fraction of the photogenerated holes have sufficient lifetime to participate in the sluggish OER, while still undergoing recombination process. ${ }^{34}$ However, these different conclusions are not contradictory. Indeed, the positive correlation of charge transfer capacitance for PEIS data and TAS peak magnitude for bare hematite photoanodes has shown that both signals arise from the same origin. ${ }^{34}$

Despite this encouraging progress made to date, much remains to be understood about the true role of different cocatalysts, given that multiple dynamic pathways are possible for the photo-generated charge carriers, as shown in Fig. S1. ${ }^{35}$ As the majority of mechanistic studies was performed on heterogeneous cocatalysts, such as $\mathrm{CoPi}$ and $\mathrm{NiFeO}_{x}$, we here explore a new molecular model system.

We first applied well-defined molecular cubanes, $\left[\mathrm{Co}_{4}{ }_{4}(\mathrm{dpy}\{\mathrm{OH}\} \mathrm{O})_{4}(\mathrm{OAc})_{2}\left(\mathrm{H}_{2} \mathrm{O}\right)_{2}\right]\left(\mathrm{ClO}_{4}\right)_{2}\left(\right.$ denoted as $\left.\mathrm{C}_{1}\right)$ as model cocatalysts and explored their functionality on hematite photoanodes through systematic photoelectrochemical characterizations and rate law analyses of the surface charge transfer process. Three key questions in the emerging field of molecular photoanodes are investigated in the following: (1) What is the role of the molecular cubanes, and how do they relate to previous systems?29,36,37 (2) Can we apply the observed features to other cobalt based molecular and heterogeneous cocatalysts? (3) How stable are these molecular cocatalysts on hematite photoanode surfaces? $3^{8}$
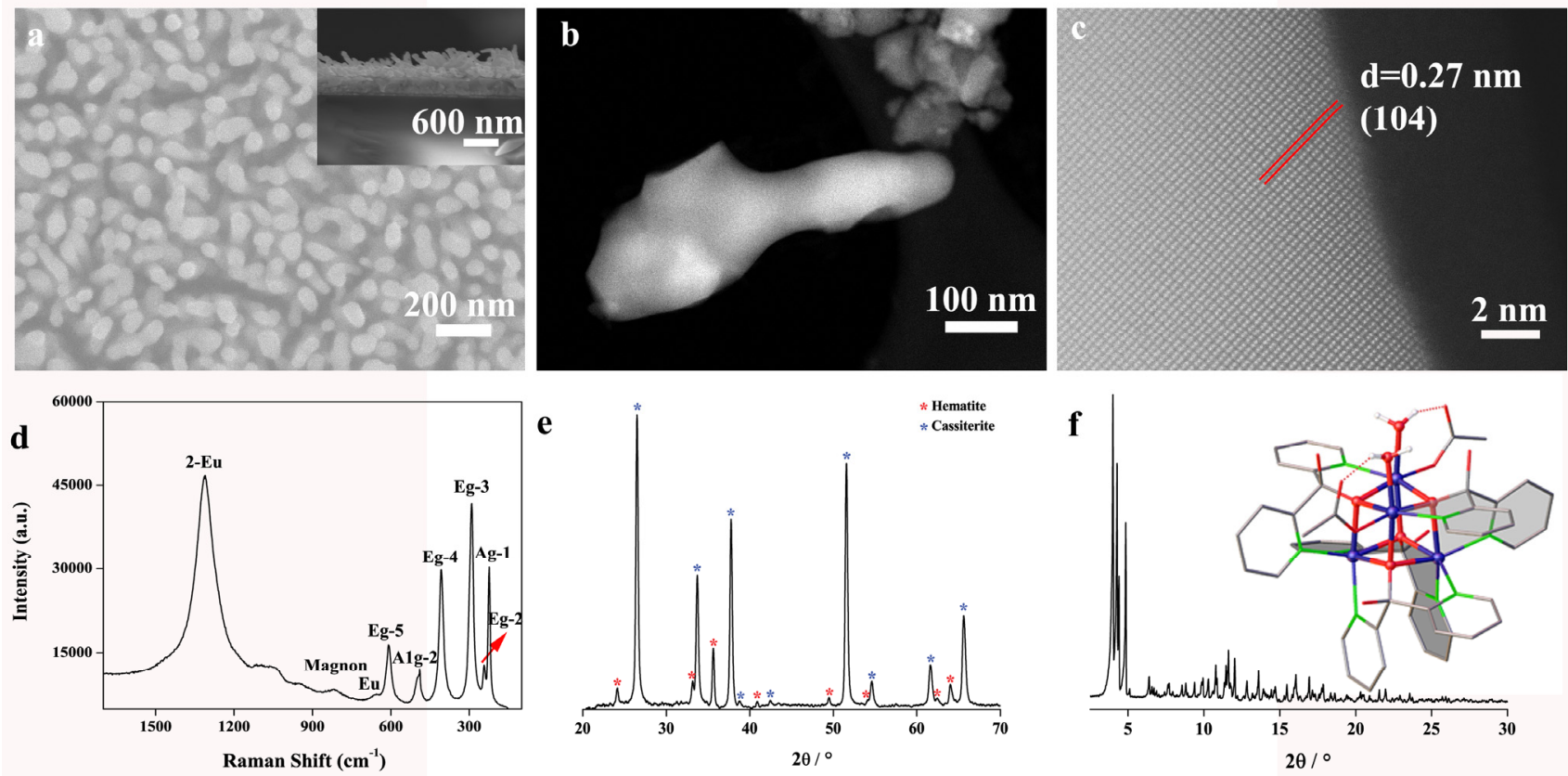

Figure 1. Characterization of prepared hematite photoanodes: (a) Representative top view SEM image and cross-section (inset) of the hematite thin film, (b) HAADF-STEM image of hematite nanorods, and (c) magnified image with atomic resolution, (d) Raman spectrum, (e) thin film XRD pattern of hematite, and (f) powder XRD pattern of the molecular cocatalyst $\mathrm{C}_{1}$ (inset: crystal structure of $\mathrm{C}_{1}$; Co: dark blue, C: gray, O: red, N: green, $\mathrm{H}$ : white). 


\section{Results and discussion}

Preparation of cocatalyst-modified photoanodes and their photoelectrochemical properties. Hematite photoanodes were prepared according to literature protocols (see SI for details). ${ }^{39,40}$ Scanning electron microscopy (SEM) images show a uniform nanorod array on top of the FTO glass (Fig. 1a).

The nanorod morphology was further characterized by scanning transmission electron microscopy (STEM) using a high-angle annular dark field (HAADF) detector (Fig. 1b). The HAADF-STEM micrograph in Fig. 1c shows high crystallinity of the hematite particles, which was further verified by the well-defined characteristic Raman spectrum (Fig. 1d) and by thin film X-ray diffraction (XRD) patterns (Fig. 1e and details in Fig. S2). Results from the optical absorbance spectrum yield a calculated band gap of $E_{g} \approx 2.08 \mathrm{eV}$ (Fig. S3), which agrees with reported values for hematite. ${ }^{41}$ Further details on the Raman, XRD and optical methods can be found in the SI. All prepared hematite photoanodes were screened before loading of cocatalysts, and only substrates with similar photoelectrochemical properties (current density error $\leq 5 \%$ at $1.23 \mathrm{~V} v s$. RHE) were used for further tests.

We here selected the molecular cubane water oxidation catalyst $\left[\mathrm{Co}_{4}{ }_{4}(\mathrm{dpy}\{\mathrm{OH}\} \mathrm{O})_{4}(\mathrm{OAc})_{2}\left(\mathrm{H}_{2} \mathrm{O}\right)_{2}\right]\left(\mathrm{ClO}_{4}\right)_{2}, \mathrm{C}_{1}$ as a model cocatalyst (cf. powder XRD data in Fig. If, more information in Fig. $\mathbf{S}_{\mathbf{4}}, \mathbf{5}$ ). This cubane was proven to be stable under photochemical water oxidation conditions and excels though the essential $\left\{\mathrm{H}_{2} \mathrm{O}-\mathrm{Co}_{2}(\mathrm{OH})_{2}-\mathrm{OH}_{2}\right\}$ edge-site motif that is crucial for water oxidation on cobalt oxide surfaces..$^{42}$ Different amounts of $C_{1}$ were then casted onto hematite surfaces using Nafion as binding material, ${ }^{43,44}$ and the $C_{1}$ loading density was varied from 3.3 to $53.3 \mathrm{nmol} \mathrm{cm}{ }^{-2}$ (more details in SI). The pristine, Nafion modified and $C_{1}$ loaded hematite photoanodes were denoted as $\mathrm{H}, \mathrm{H}-\mathrm{N}$ and $\mathrm{H}-\mathrm{N}-\mathrm{C}_{1}-\mathrm{x}(\mathrm{H}=$ hematite, $\mathrm{N}=$ Nafion, $\mathrm{x}$ represents the loading density), respectively. Linear sweep voltammetry (LSV) data was first recorded for all photoanodes under simulated solar irradiation (Fig. 2a). As expected, loading of $C_{1}$ cocatalysts had the beneficial effect of a lower photocatalytic onset potential, while the cathodic shifts were comparable $(\sim 220 \mathrm{mV})$, i.e. rather independent on the loading density (Fig. S1o). 45 A loading of $26.7 \mathrm{nmol} \mathrm{cm}^{-2}$ delivered the best activity, namely 9-fold higher than that of H-N at $1.23 \mathrm{~V}$ vs. RHE. LSV data recorded under dark conditions (Fig. Sir) further confirmed the beneficial role of $C_{1}$ loading during the photocatalytic process.

Identification of the cocatalyst functionality with IM-TPS: Hole storage reservoirs vs. catalytic centers. TPS is a technique that not only bridges the boundaries between photoelectrochemical and electrochemical domains, but also connects transient and steady-state processes (Fig. S12, cf. SI for further details). ${ }^{46}$ To elucidate the function of the applied cubane cocatalysts $C_{1}$, the amount of charges passed through the photoanode during the anodic $\left(Q_{\text {anodic }}\right)$ and cathodic $\left(Q_{\text {cathodic }}\right)$ transient process are given in Fig. 2b. ${ }^{47}$ Clearly, both the applied bias and $C_{1}$ loading play significant roles in the evolving trends of both parameters. Prior to the onset potential, the magnitudes of both $Q_{\text {anodic }}$ and $Q_{\text {cathodic }}$ are comparable and negligible for all photoanodes, indicating that $C_{1}$ has no noticeable function. When the applied potential is higher than the onset potential of the $C_{1}$ loaded photoanode, but still lower than that of bare hematite, both $Q_{a n o d i c}$ and $Q_{\text {cathodic }}$ for bare hematite remain negligible while they increase significantly for $\mathrm{C}_{1}$ loaded photoanodes. For example, at $0.9 \mathrm{~V} v$ s. RHE, bare hematite has negligible $Q_{\text {anodic }}$ and $Q_{\text {cathodic }}$ values of 14.4 and $9.6 \mu \mathrm{C} \mathrm{cm}^{-2}$ respectively, while the values are 351.1 and $258.0 \mu \mathrm{C} \mathrm{cm}^{-2}$, respectively, as a result of $26.7 \mathrm{nmol} \mathrm{cm}^{-2} \mathrm{C}_{1}$ loading, indicating a significant hole storage capacity. The slight discrepancy of both values further implies that these cocatalysts are probably acting more strongly as hole reservoirs than as catalytic centers.
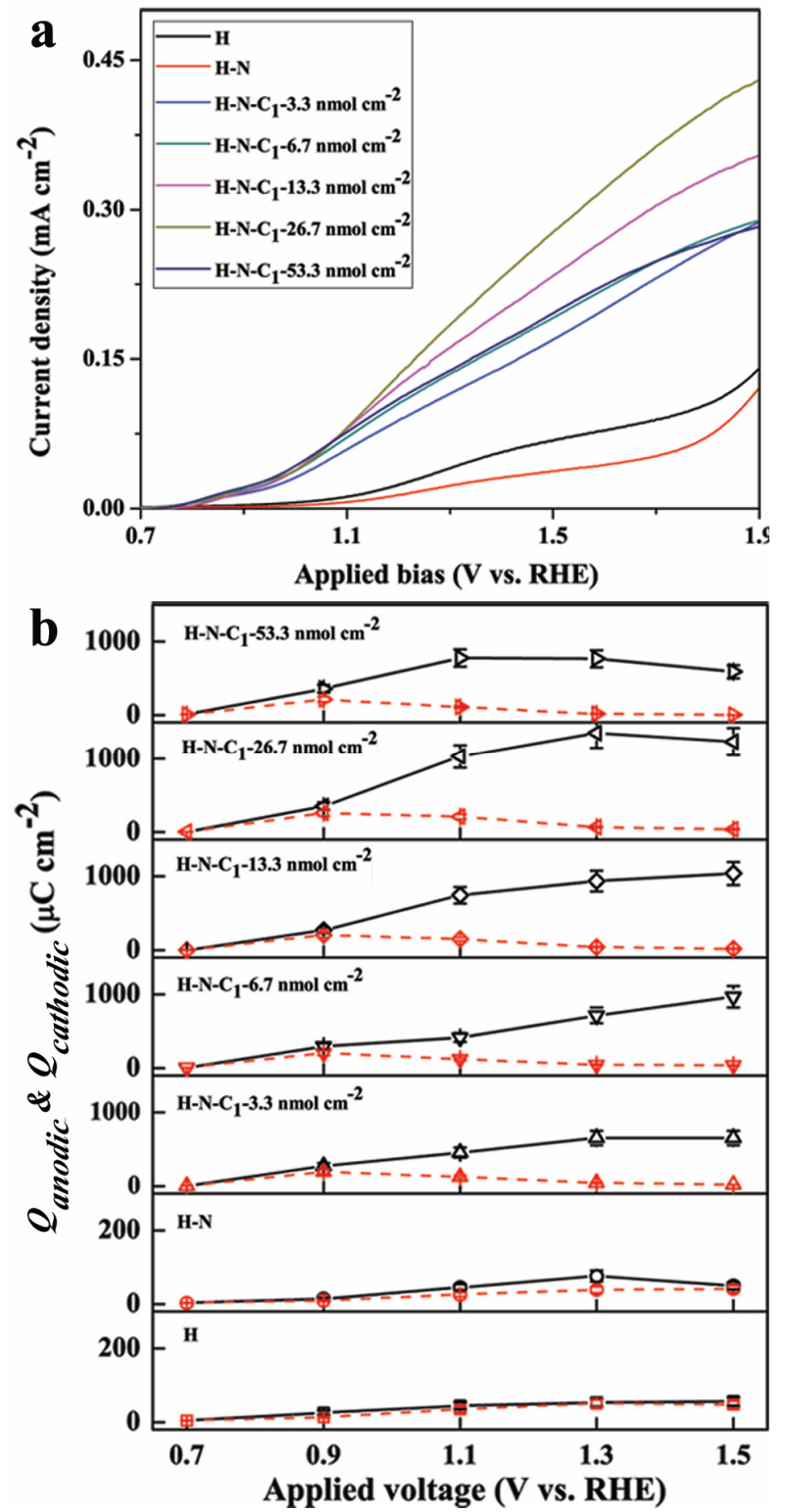

Figure 2. (a) LSV curves of bare and $C_{1}$ loaded photoanodes and (b) respective transient $Q_{\text {anodic }}, Q_{\text {cathodic }}$ (black solid and red dashed lines $=$ anodic and cathodic processes, respectively). 


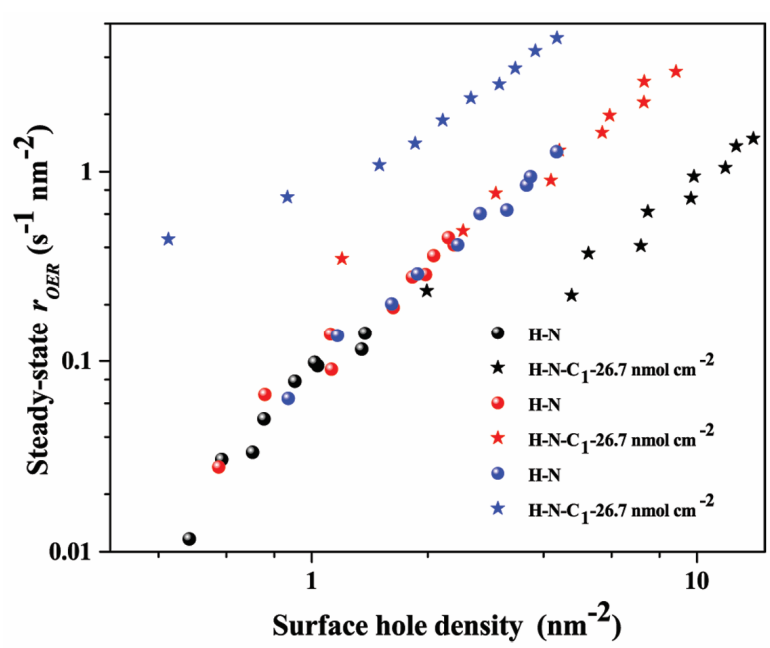

Figure 3. Rate law analysis of bare and $C_{1}$ loaded $(26.7 \mathrm{nmol}$ $\mathrm{cm}^{-2}$ ) photoanodes at 0.9, 1.1 and $1.3 \mathrm{~V}$ vs. RHE (black, red and blue symbols, respectively), steady-state OER rates $\left(r_{O E R}\right)$ and surface hole densities were probed by IM-TPS.

To verify this hypothesis, intensity modulated TPS (IMTPS, 6-100 $\mathrm{mW} \mathrm{cm}^{-2}$ ) experiments were performed (more information in Fig. S14-15), where the steady-state photocurrent density $\left(J_{s s}\right)$ could be interpreted as the OER rate $\left(r_{O E R}\right)$, and the corresponding steady-state surface hole density could be probed by monitoring the magnitude of $Q_{\text {cathodic }}{ }^{34}$ Thus, rate law analysis was performed to identify the apparent reaction rate constant $\left(k_{\text {app }}\right)$, and reaction order for surface accumulated holes (Equation S1, cf. SI for more details). As shown in Fig. 3, the $C_{1}$ loaded photoanode displays an identical reaction order of $\sim 2$ with bare hematite for surface accumulated holes, exhibiting a lower $k_{a p p}$ (o.02 and 0.08 hole $^{-1} \mathrm{~nm}^{2} \mathrm{~s}^{-1}$, respectively). This implies that the OER proceeds predominantly through hematite surface states, involving accumulation of two holes for the rate determining step. ${ }^{19,48}$
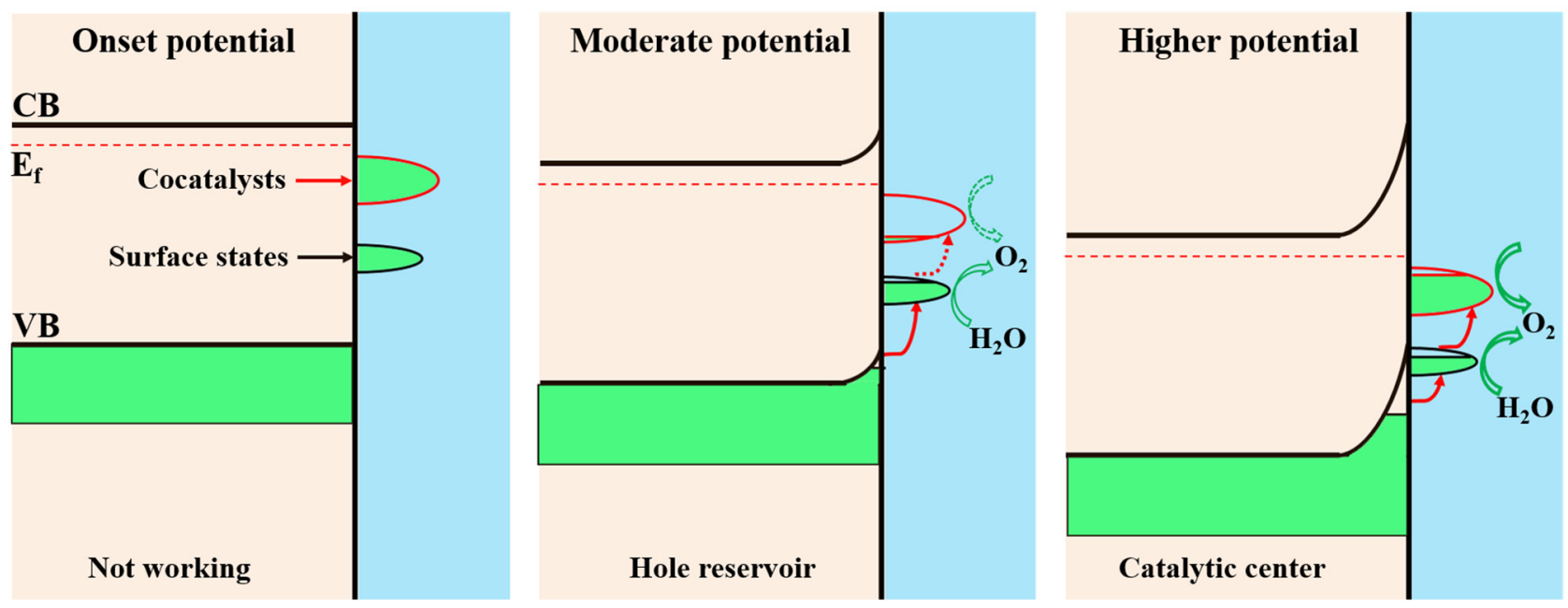

Figure 4. Schematic demonstration of the transforming role of $C_{1}$ with increasing applied bias at steady-state operations under light illumination. Around the onset potential, almost all photo-generated charge carriers are subject to recombination; at moderate potentials, surface cocatalysts are activated to store large amount of photo-holes while unable to transfer them efficiently to electrolyte; at higher potentials, surface cocatalysts are able to transfer photo-holes efficiently without much storage (dashed arrows: very slow or kinetically negligible processes, solid arrows: fast processes.). 
Dynamics of anodic decay. Other than the most widely used TAS method for monitoring the dynamics of photogenerated holes, both anodic and cathodic transient decay TPS curves directly probe the dynamics of photogenerated electrons. Despite their difference in the working principle, united kinetics were reported for the charge carriers. ${ }^{3449}$ Actually, the anodic transient decay exhibits an exponential nature for all photoanodes, which represents the dynamic interplay of multiple underlying processes. In current experimental setups, it is very hard to fully interpret the whole dynamic spectrum, particularly when considering that different sites for hole accumulation, transfer and recombination are involved. Interestingly, the recorded anodic transient curves could be well fitted with a biphasic exponential decay model, a fast process coupled with a slow one. Their characteristic decay constants can be approximately treated as the interplay of forward charge accumulation/transfer rate constant $\left(k_{\text {anodic-ct }}\right.$, result of both charge accumulation, $k_{\text {acc }}$ and charge transfer, $k_{O E R}$ ) with backward recombination rate constant $\left(k_{\text {anodic-rec }}\right)$ at fast $\left(k_{a-}\right.$ nodic-ctt and $\left.k_{\text {anodic-rec }}\right)$ and slow ( $k_{\text {anodic-ct } 2}$ and $\left.k_{\text {anodic-rec } 2}\right)$ decay stages (SI for details, equations S2-8). ${ }^{34,50}$ To exclude any $\mathrm{OH}^{-}$diffusion effect on the slow decay phase, a buffered electrolyte (borate buffer, $50 \mathrm{mM}$ ) was used exclusively for all measurements..$^{51}$ Additionally, constant two-phase transient decay behavior was observed at elevated $\mathrm{pH}$ values (Fig. S19).

The evolution of both rate constants significantly depends on several factors, such as $C_{1}$ loading, applied bias and the decay phase. To clarify the function of the cocatalysts, the results are discussed in the following with respect to the function of applied bias and phase of decay.

At o.9 V vs. RHE, comparable overall $k_{\text {anodic-ct }}$ were obtained during the fast decay phase for all photoanodes (Fig. 5a), which indicates that the charging kinetics of $C_{1}$ and hematite surface state are indistinguishable when assuming that the charge accumulation process is predominant. In this case, abundant $C_{1}$ active sites would act as additional hole storage reservoirs. Meanwhile, the decreased $k_{\text {anodic-rec }}\left(1.78\right.$ and $1.14 \mathrm{~s}^{-1}$ respectively for $\mathrm{H}-\mathrm{N}$ and $\mathrm{H}-\mathrm{N}-\mathrm{C}_{1}-$ $26.7 \mathrm{nmol} \mathrm{cm}^{-2}$, Fig. 5b) revealed a positive role of $\mathrm{C}_{1}$ in mitigating electron-hole recombination kinetics. The magnitudes of both $k_{\text {anodic-ct }}$ and $k_{\text {anodic-rec }}$ indicate a relatively high charge carrier density at this moment, and the recombination process is the major option ( $k_{\text {anodic-rec }}>k_{\text {anodic-ct }}$ ) for photogenerated charge carriers for all photoanodes. In comparison, the magnitudes of both $k_{\text {anodic-ct } 2}$ and $k_{\text {anodic-rec }}$ are much smaller in the slow decay phase which reveals that only a very small percentage of charge carriers are remaining. ${ }^{52}$ The abnormally higher $k_{\text {anodic-ct }}$ derived for bare and low $C_{1}$ loaded photoanodes at lower bias highlights the difficulty for separation of charge accumulation and transfer processes (Fig. 6a), so that an unambiguous assignment of the cocatalyst function is challenging at this stage. Nevertheless, it is clear that $C_{1}$ is still capable of reducing recombination process as $k_{\text {anodic-rec }}(\mathbf{F i g} . \mathbf{6 b})$ keep decreasing.

Overall, these long-lived holes still have a stronger tendency for recombination $\left(k_{\text {anodic-rec } 2}>k_{\text {anodic-ct }}\right)$ during the slow decay phase, which is possibly due to the inability to

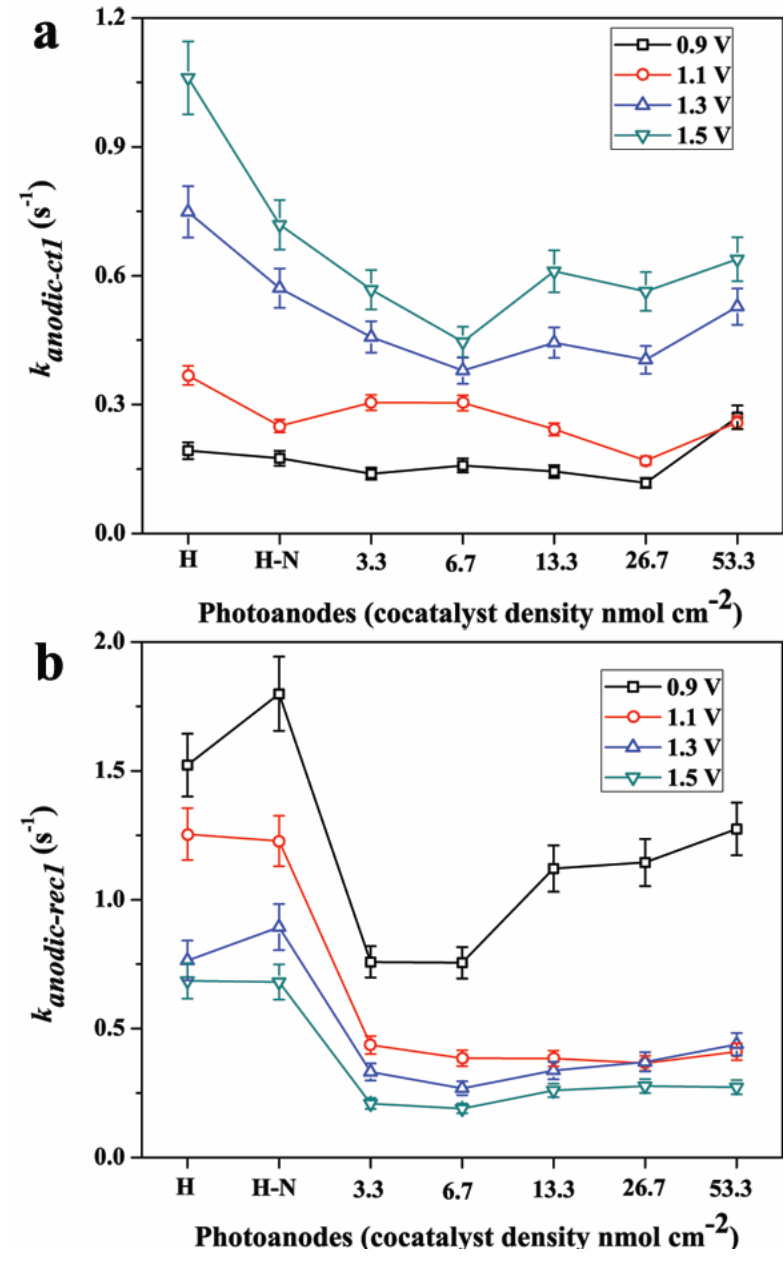

Figure 5. Anodic fast decay phase for (a) forward hole accumulation/transfer rate constants $k_{\text {anodic-ct }}$ and (b) electronhole recombination rate constants $k_{\text {anodic-rec }}$.

empty the trapped electrons in the hematite intrabandstates.

At high applied bias (1.3 V vs. RHE), the depletion of trapped electrons would significantly retard the recombination process for all photoanodes, which is supported by the reduced magnitudes of both $k_{\text {anodic-rec }}$ and $k_{\text {anodic-rec } 2 \text {. }}$ When comparing to the bare photoanode, the addition of $\mathrm{C}_{1}$ further facilitates the overall charge separation process as indicated by smaller $k_{\text {anodic-rec }}\left(0.89\right.$ and $0.35 \mathrm{~s}^{-1}$ respectively for $\mathrm{H}-\mathrm{N}$ and $\mathrm{H}-\mathrm{N}-\mathrm{C}_{1}-26.7 \mathrm{nmol} \mathrm{cm}{ }^{-2}$, Fig. 5b) despite the reduced $k_{\text {anodic-ct }}(\mathbf{F i g}$. $5 \mathbf{a})$. In the slow decay phase, it is surprising that $k_{\text {anodic-rec }}$ is remarkably stable for all photoanodes (Fig. 6b), pointing out that the recombination process is indeed greatly retarded through the efficient extraction of generated electrons by the applied electric field. Surface loaded $C_{1}$ participates in the water oxidation process, because higher $J_{s s}$ is obtained (Fig. S16) although $k_{a-}$ nodic-ctz decays slightly (Fig. 6a). In this case, these remnant long-lived holes are mostly transferred for OER $\left(k_{\text {anodic-ct }}>\right.$ $\left.k_{\text {anodic-rec } 2}\right)$. The kinetic analysis of the anodic transient process again highlights the transformation of the cocatalyst role as a function of the applied bias (Fig. 4). Furthermore, the two- phase decay model reveals a similar dynamic role 

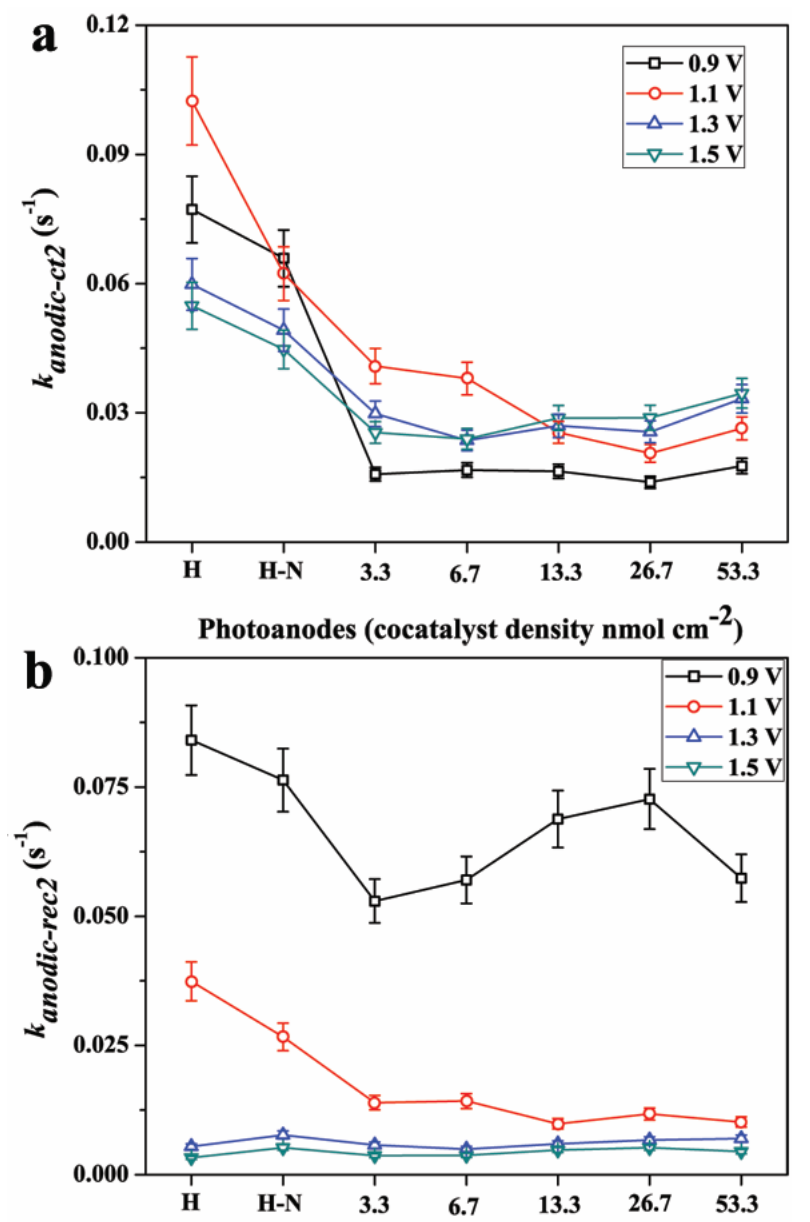

Photoanodes (cocatalyst density $\mathrm{nmol} \mathrm{cm}^{-2}$ )

Figure 6. Anodic slow decay phase for (a) forward hole accumulation/transfer rate constants $k_{\text {anodic-ctz }}$ and (b) electronhole recombination rate constants $k_{\text {anodic-rec } 2}$.

of the cocatalyst even at constant bias, which is determined by the changing charge carrier populations. Nevertheless, it remains very challenging to fully interpret the whole dynamic spectrum of charge carrier density, especially when considering all involved factors, namely both types of catalytic centers, hematite surface states ${ }^{53,54}$ and surface loaded $\mathrm{C}_{1} .{ }^{55}$ All of the above analyses from both a steadystate and a dynamic perspective enable us to understand the transformation of the cocatalyst role in a qualitative manner.

Dynamics of cathodic decay. Similar to the anodic transient decay process, the above applied biphasic description of the exponential decay behaviour could also be well employed for the cathodic decay part, so that the same analytical strategy was applied (equations S2-8). Clearly, the amplitudes of both recombination rate constants $k_{c a}$ thodic-rect and $k_{\text {cathodic-rec2 }}$ are much larger than corresponding hole transfer rate constant $k_{\text {cathodic-ct } 1}$ and $k_{\text {cathodic-ct } 2}$ values for all photoanodes at all applied biases (Fig. S2o-21), which indicates the dominant role of recombination during the cathodic decay process. This is in stark contrast to the observations during the anodic process, especially at high bias, thus indicating substantial differences in the underlying kinetics. Meanwhile, the reduction of both $\boldsymbol{k}_{\text {cathodic-rec }}$ and $k_{\text {cathodic-rec } 2}$ for $\mathrm{C}_{1}$ loaded photoanodes again highlights the positive role of the cocatalyst in reducing the recombination kinetics. In addition, kinetic analyses of this cathodic current density decay actually point out that the recombination rate is depending on the charge carrier concentration. At low and medium applied biases, $C_{1}$ loaded photoanodes are following higher recombination orders (higher decay slope) than their bare photoanode counterparts (Fig. S22-24). In comparison, similar recombination orders are obtained at high bias (Fig. S25). This agrees well with the respective $Q_{\text {cathodic }}$ evolution behaviour, thus indicating that the stored holes in $C_{1}$ are not exempted from recombination. The interesting 'self-limiting' phenomenon of surface accumulated holes underscores the dynamic as well as balancing role of loaded $C_{1}$ for providing catalytic and recombination centers.

Verification of cocatalyst functionality by PEIS. PEIS is another powerful and versatile analytical approach to probe surface charge carrier concentrations under pseudo-steady state conditions. To validate the dynamic functionality of the cocatalysts proposed above, PEIS was conducted at a wide range of applied bias for all prepared photoanodes. Two semicircles are present in the Nyquist plots for all photoanodes at 1.3 V vs. RHE (Fig. S26), and the second semicircle (high impedance at low frequency) for $C_{1}$ loaded photoanodes is much smaller than that of the bare photoanode, indicating the important role of $C_{1}$ in lowering the charge transfer resistance. To understand quantitatively the variation of charge carrier concentrations, a simplified equivalent circuit (EC) (Fig. S26 inset) was chosen for PEIS data interpretation as the second semicircles of the Nyquist plots significantly changes with $C_{1}$ loading. This is similar to previous observations for $\mathrm{CoPi}$ as cocatalyst. ${ }^{29,56,57}$ The evolution of the fitted charge transfer capacitance $\left(C_{c t}\right)$ for both bare and $C_{1}$ loaded photoanodes (Fig. 7) significantly mimics the behavior of the respective $Q_{\text {cathodic }}$ determined with TPS (Fig. 2b), which

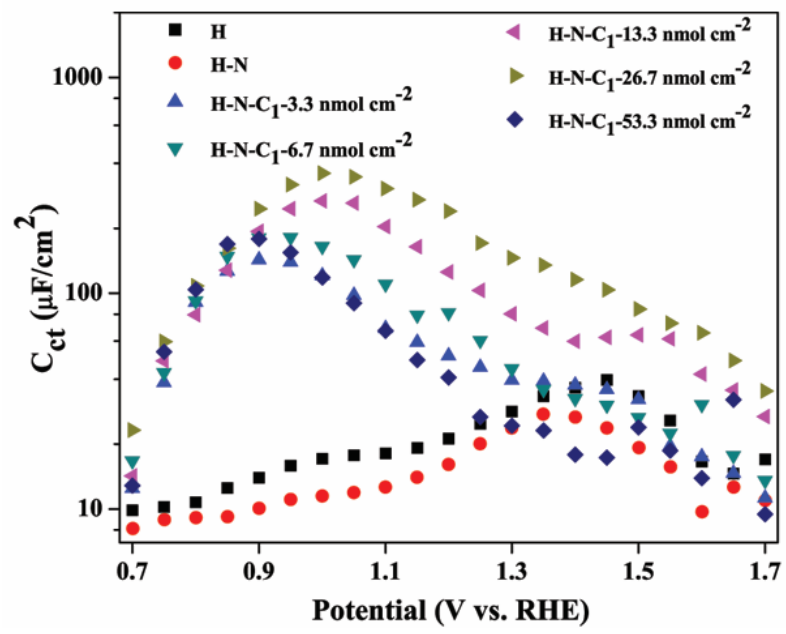

Figure 7. $C_{c t}$ values for $C_{1}$ loaded and bare hematite photoanodes measured under AM $1.5 \mathrm{G}$ simulated sunlight at $100 \mathrm{~mW} \mathrm{~cm}^{-2}$ in $0.05 \mathrm{M}$ borate buffer (pH 8.5). 
again underscores a plausible functionality transition of the applied $C_{1}$ cocatalysts. Similar to the IM-TPS approach used above, intensity modulated EIS (IM-EIS) was performed to modulate the $C_{c t}$, which could be applied to estimate the corresponding surface hole density (Equation S9 and more details in the SI). Therefore, an analogous strategy for rate law analysis (Equation S1) was applied to compare both $k_{\text {app }}$ and reaction order evolution as a function of cocatalyst loading and applied bias (Fig. 8a). Interestingly, the applied bias dependent log-log dependent behaviour of $C_{1}$ loaded photoanodes bears close analogy to the dynamic features derived from IM-TPS analyses, except that higher surface hole densities were probed, which reflects the resolution difference of both techniques. Nevertheless, the IM-EIS analysis again highlights the transformation of the cocatalyst functionality from active hole storage centers to catalytic sites (Fig. 4).

From a kinetic perspective, both the charge transfer rate constant $\left(k_{c t}\right)$ and the recombination rate constant $\left(k_{r e c}\right)$ derived from PEIS are inversely proportional to the respective charge transfer resistance $\left(R_{c t}\right.$, Fig. $\left.\mathbf{S}_{27}\right)$ and the bulk resistance $\left(R_{\text {bulk }}\right.$, Fig. S28b).$^{58}$ Equation S1o was used to estimate the dynamic interplay of $k_{c t}$ and $k_{\text {rec }}$. Obviously, the recombination process is the major option for charge carriers in all photoanodes at low biases as the ratio of both rate constants is always below $50 \%\left(k_{c t}<k_{\text {rec }}\right)$ (Fig. 8b). However, $3.3 \mathrm{nmol} \mathrm{cm}^{-2}$ of $\mathrm{C}_{1}$ loading already promotes and stabilizes this ratio, and it deteriorates at higher $C_{1}$ loading. This interesting phenomenon demonstrates that $C_{1}$ is not only storing photo-generated holes, but also provides recombination sites. As the applied bias increases, the ratio raises fast, especially for $C_{1}$ loaded photoanodes and OER becomes dominant at the point where the ratio exceeds 50 $\%\left(k_{c t}>k_{\text {rec }}\right)$. This kinetic PEIS analysis is in line with previous kinetic analysis of TPS data. In addition, there is no significant flat band potential change for these $C_{1}$ loaded photoanodes and bare ones, as indicated by the MottSchottky (MS) plots in Fig. S29. This implies that $C_{1}$ loading does not alter the interfacial energetics of photoanodes, which is in line with previous investigations employing CoPi as surface cocatalyst. ${ }^{29,59}$

Viability of the dynamic concept of the cocatalyst role. The previously published molecular cubane water oxidation catalysts $\left[\mathrm{Co}_{4}{ }_{4}(\mathrm{hmp})_{4}(\mu-\mathrm{OAc})_{2}\left(\mu_{2}-\mathrm{OAc}\right)_{2}\left(\mathrm{H}_{2} \mathrm{O}\right)_{2}\right]$ $\left(\mathrm{C}_{2}\right.$, Fig. S6-7) $(\mathrm{hmp}=2 \text {-(hydroxymethyl)pyridine })^{60}$ and $\left[\mathrm{Co}_{3}{ }_{3} \mathrm{Er}(\mathrm{hmp})_{4}(\mathrm{OAc})_{5} \mathrm{H}_{2} \mathrm{O}\right]\left(\mathrm{C}_{3} \text {, Fig. S8-9 }\right)^{61}$ as well as heterogeneous cobalt oxide $\left(\mathrm{CoO}_{x}\right.$, referred to as $\left.\mathrm{C}_{4}\right)$ were also loaded on the screened photoanodes. These cobalt-based cocatalysts were capable of decreasing onset potentials and increasing photoelectrochemical activities to different extents (Fig. S3o and Table S1). First, similar TPS and IMTPS measurements were conducted and summarized in Fig. S31-33, S40-42, and S49-51. Interestingly, the evolution of the related TPS parameters and IM-TPS rate law analyses clearly display the general features observed for $C_{1}$, regardless of the molecular or heterogeneous nature of the initial cocatalyst. Subsequent kinetic information during both anodic and cathodic decay processes was also derived and interpreted using the previous bi-phasic model.
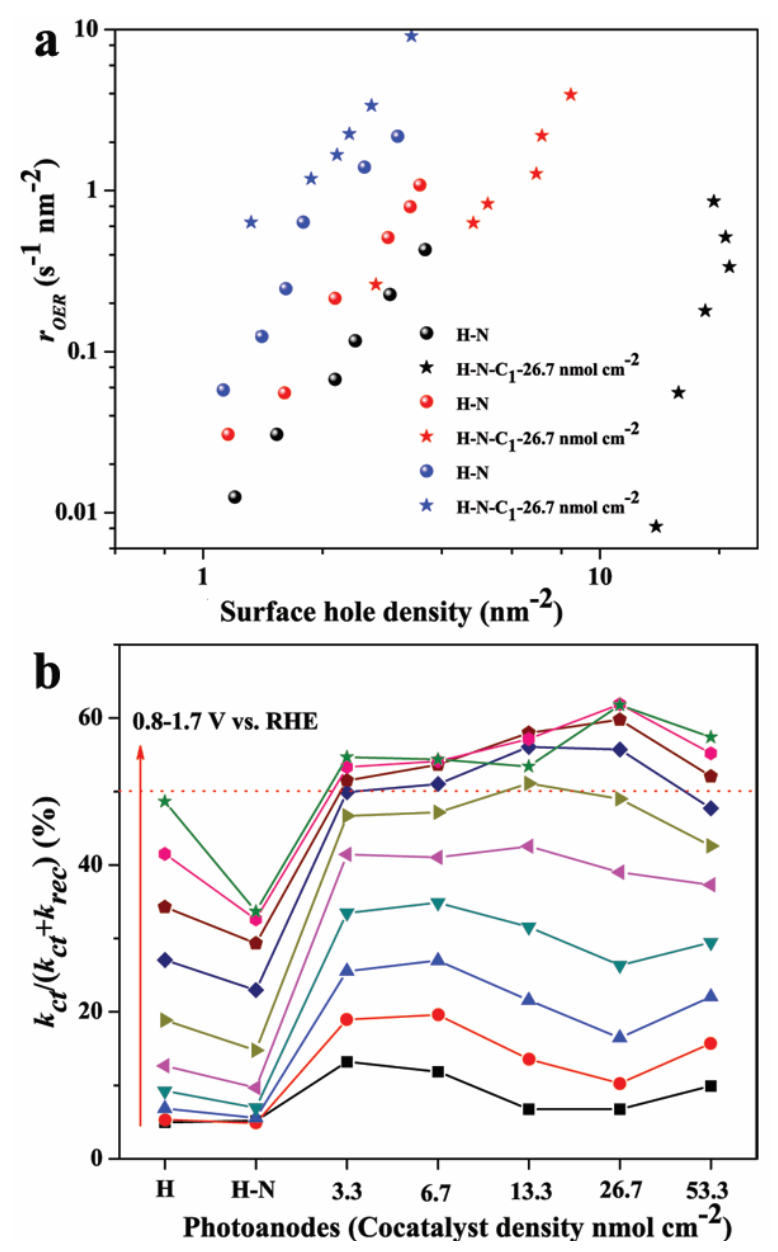

Figure 8. (a) Rate law analysis of bare and $C_{1}$ loaded (26.7

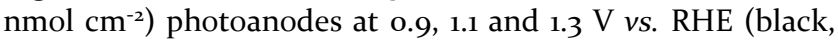
red and blue color, respectively), $r_{O E R}$ and surface hole densities were probed by IM-EIS, (b) kinetic analysis as the function of cocatalysts loading and applied bias.

Despite the differences in absolute magnitude, a very similar evolution behaviour emerged for the characteristic kinetic parameters (Fig. S34-37, $\mathbf{S}_{\mathbf{4 3}-\mathbf{4 7}}$ and $\mathbf{S}_{\mathbf{5 2}} \mathbf{- 5 5}$ ). Thereafter, all of these cocatalyst modified photoanodes were subjected to PEIS and IM-EIS measurements under the same operating conditions. The corresponding $C_{c t}$ (Fig. $S_{3} 8, S_{47}$ and $S_{56}$ ) and rate law features (Fig. S39, $S_{48}$ and $\left.S_{57}\right)$ largely reproduce the characteristics probed from TPS and IM-TPS, respectively. In conclusion, an analogous dynamic functionality behaviour can be observed for four different cocatalysts loaded on hematite photoanode surfaces.

Photocatalytic stability of photoanodes loaded with molecular cocatalysts. We furthermore performed stability investigations on the above-mentioned modified photoanodes..$^{10,11,62}$ Firstly, the CV-controlled potential photoelectrolysis (CPE, at 1.3 V vs. RHE)-CV cycles were implemented. Compared to the stable hematite photoanode (Fig. S58), the slow photocurrent density decay of photoanodes loaded with molecular cocatalysts (Fig. S59a, S6oa and S61a) 


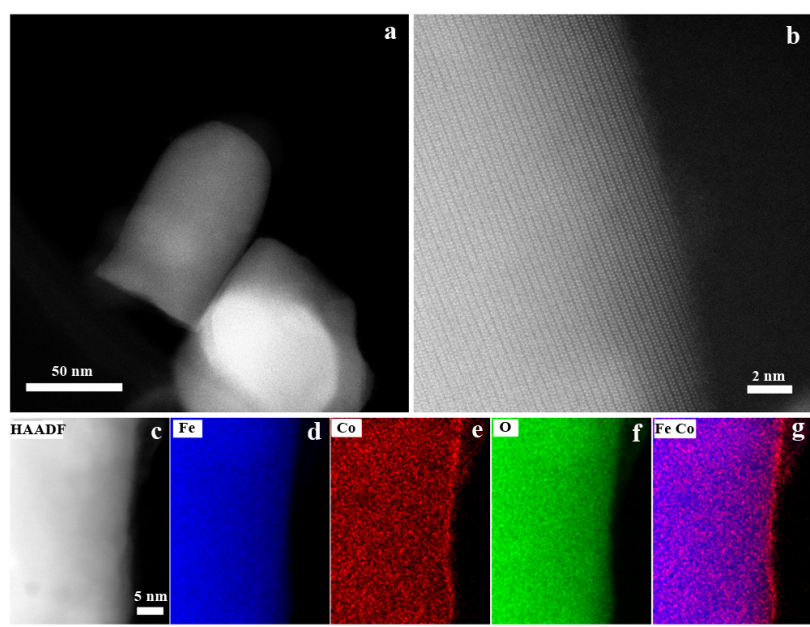

Figure 9. STEM-HAADF analysis of the hematite surface loaded with $\mathrm{C}_{1}$ after aging at $1.3 \mathrm{~V}$ vs. RHE (a), magnified image (b), selected area HAADF (c) and EDX elemental maps of Fe (d), Co (d), O (f), Fe and Co (g), scale bars for (c)-(g) are the same.

could possibly be explained by either transformation of these surface molecular cocatalysts or generation of oxygen bubbles which gradually block the effective surface area (Fig. S62). We can exclude the bubble effects due to the observation that the characteristic $\mathrm{Co}^{2+} / \mathrm{Co}^{3+}$ redox potentials of the electrode modified with molecular cocatalysts remain unchanged before and after $5 \mathrm{~h}$ of stability tests (Figure $\mathbf{S}_{59} \mathbf{b}$, S6ob and $\mathbf{S 6 1 b}$ ), which indicates that these surface species are predominantly remaining in their initial molecular state (the prevailing presence of molecular species up to $1.3 \mathrm{~V}$ of applied bias is further discussed in the SI).

Next, STEM coupled with energy-dispersive X-ray spectroscopy (EDX) analysis was carried out to probe $C_{1}$ stability after different applied bias. There were no particular species that could be identified after aging at $1.3 \mathrm{~V}$ vs. RHE (Fig. 9a-b), and EDX elemental maps of Fe, Co and oxygen (Fig. 9c-g) clearly indicate an uniform cobalt distribution on the hematite surface. However, a thin layer of small clusters could be identified on the hematite surface after aging at 1.7 V vs. RHE (Fig. S63a-b), and they might be assigned to $\mathrm{CoO}_{\mathrm{x}}$ species due to their cobalt enrichment (see EDX elemental maps in Fig. S63c-g). Similar stability features were also concluded from X-ray photoelectron spectroscopy (XPS) investigations (Fig. S65-66 and more details in the SI). It is important to mention that the gradual decomposition of molecular species at $1.3 \mathrm{~V}$ vs. RHE is inevitable (as indicated by XPS data), but it is a very slow process. For the (photo)electrochemical analyses we applied here, data acquisition takes a short time period (minute scale) and a fresh electrode was employed for every data set. Thus, it is safe to conclude that the molecular species are the dominant active species during data collection and that the observed functionality transition is representing the behavior of molecular species.

\section{Conclusions}

In this work, three fundamental questions of molecular cocatalysts for water oxidation were newly addressed, namely, (1) their role on photoanode surfaces, (2) transferable concepts for their functionality, (3) their operational stability. Hematite photoanodes loaded with the molecular cobalt cubane $\left\{\mathrm{Co}_{4}{ }_{4}(\mathrm{dpy}\{\mathrm{OH}\} \mathrm{O})_{4}(\mathrm{OAc})_{2}\left(\mathrm{H}_{2} \mathrm{O}\right)_{2}\right\}$ as a new model cocatalyst system were investigated with comprehensive (photo)electrochemical analyses (LSV, TPS and PEIS) and related rate law analyses (IM-TPS and IM-EIS).

(1) We observed enhanced performance of hematite after molecular cocatalyst loading. For the first time, our results point to an interesting dynamic functionality of molecular cocatalysts as a function of the applied potential. The role of the cocatalysts is transformed from predominant hole reservoirs to catalytic centers. We newly observed that this complex role results in an overall dynamic functionality of cocatalysts. This was in particular evidenced from the kinetic analysis of both TPS and PEIS data.

(2) Most importantly, we observed these trends for other molecular $\left\{\mathrm{Co}(\mathrm{II})_{4} \mathrm{O}_{4}\right\}$ cubanes and for heterogeneous cobalt oxide cocatalysts.

(3) Furthermore, the stability of the applied surface molecular cubane $\left\{\mathrm{Co}_{4}{ }_{4}(\mathrm{dpy}\{\mathrm{OH}\} \mathrm{O})_{4}(\mathrm{OAc})_{2}\left(\mathrm{H}_{2} \mathrm{O}\right)_{2}\right\}$ cocatalysts was monitored with complementary STEM and XPS methods, and the precise onset of heterogeneous $\mathrm{CoO}_{x}$ species formation was identified at higher operation potentials.

As for design perspectives, the cocatalysts could accumulate large amounts of holes at low bias (o.9 V vs. RHE), but they were less efficient in transferring these holes for the OER process, which might be due to the slow formation kinetics of high valent species such as $\mathrm{Co}^{\mathrm{IV}}=\mathrm{O} .55$ This renders development of cocatalysts that could stabilize these high valent intermediates at relatively low applied potentials a key optimization target.

It is, however, important to note that the complex dynamic nature of the semiconductor/cocatalyst/electrolyte interfaces (interplay of multiple kinetic processes, involving accumulation, transfer and recombination of charge carriers etc.) still makes it difficult to unambiguously assign the general role of cocatalysts. Further investigations are therefore required that combine insight from different technical angles with theoretical calculations to establish a full description of such challenging hybrid systems.

Our work paves the way to combine the inexhaustible ligand engineering possibilities of molecular catalysts ${ }^{63-67}$ with the rapidly developing field of photoelectrodes. This opens up tremendous possibilities for the targeted design of a new generation of tailored solar-driven devices. 


\section{ASSOCIATED CONTENT}

Supporting Information. Supporting information is provided that includes experimental details, XRD, SEM, UV-Vis, ATR-FTIR, Raman, STEM, XPS, (photo)electrochemical characterizations and related details of rate law analyses. This material is available free of charge via the Internet at http://pubs.acs.org.

\section{AUTHOR INFORMATION}

\section{Corresponding Author}

greta.patzke@chem.uzh.ch

\section{Author Contributions}

All authors have given approval to the final version of the manuscript.

\section{Notes}

The authors declare no competing financial interests.

\section{ACKNOWLEDGMENT}

J. L., W. W., C. A. T., and G. R. P. thank the University of Zurich and the UZH research priority program Solar Light to Chemical Energy Conversion (URPP LightChEC) for financial support. G. R. P. thanks the Swiss National Science Foundation (Sinergia Grant No. CRSII2_160801/1) for financial support. R. E. acknowledges funding from the European Research Council (ERC) under EU's Horizon 2020 research and innovation program (grant agreement No. 681312). We thank Mr. Fangyuan Song for providing cubane samples, and Dr. Thomas Moehl, Prof. Dr. Chunhua Cui and Prof. Dr. David Tilley for their help with the photoelectrochemical cell and discussions.

\section{REFERENCES}

(1) Grätzel, M. Photoelectrochemical cells. Nature 2001, 414, 338-344, DOI: 10.1038/35104607.

(2) Morita, K.; Takijiri, K.; Sakai, K.; Ozawa, H. A platinum porphyrin modified $\mathrm{TiO}_{2}$ electrode for photoelectrochemical hydrogen production from neutral water driven by the conduction band edge potential of TiO2. Dalton Trans. 2017, 46, 15181-15185, DOI: 10.1039/c7dto3710d.

(3) Detz, R. J.; Sakai, K.; Spiccia, L.; Brudvig, G. W.; Sun, L.; Reek, J. N. H. Towards a Bioinspired-Systems Approach for Solar Fuel Devices. ChemPlusChem 2016, 81, 1024-1027, DOI: 10.1002/cplu.201600446.

(4) Joya, K. S.; Joya, Y. F.; Ocakoglu, K.; van de Krol, R. Watersplitting catalysis and solar fuel devices: Artificial leaves on the move. Angew. Chem. Int. Ed. 2013, 52, 10426-10437, DOI: 10.1002/anie.201300136.

(5) Berardi, S.; Drouet, S.; Francas, L.; Gimbert-Surinach, C.; Guttentag, M.; Richmond, C.; Stoll, T.; Llobet, A. Molecular artificial photosynthesis. Chem. Soc. Rev. 2014, 43, 7501-7519, DOI: 10.1039/c3cs60405e.

(6) Bae, D.; Seger, B.; Vesborg, P. C. K.; Hansen, O.; Chorkendorff, I. Strategies for stable water splitting via protected photoelectrodes. Chem. Soc. Rev. 2017, 46, 1933-1954, DOI: 10.1039/c6csoog18b.

(7) Li, J.; Güttinger, R.; Moré, R.; Song, F.; Wan, W.; Patzke, G. R. Frontiers of water oxidation: The quest for true catalysts. Chem. Soc. Rev. 2017, 46, 6124-6147, DOI: 10.1039/c7csoo3o6d.

(8) Laskowski, F. A. L.; Nellist, M. R.; Qiu, J.; Boettcher, S. W. Metal Oxide/(oxy)hydroxide Overlayers as Hole Collectors and
Oxygen-Evolution Catalysts on Water-Splitting Photoanodes. J. Am. Chem. Soc. 2019, 141, 1394-1405, DOI: 10.1021/jacs.8bo9449.

(9) Wang, M.; Yang, Y.; Shen, J.; Jiang, J.; Sun, L. Visible-lightabsorbing semiconductor/molecular catalyst hybrid photoelectrodes for $\mathrm{H}_{2}$ or $\mathrm{O}_{2}$ evolution: recent advances and challenges. Sustain. Energ. Fuels 2017, 1, 1641-1663, DOI: 10.1039/C 7 SE0o222J.

(10) Zhang, B.; Li, F.; Yu, F.; Wang, X.; Zhou, X.; Li, H.; Jiang, Y.; Sun, L. Electrochemical and Photoelectrochemical Water Oxidation by Supported Cobalt-Oxo Cubanes. ACS Catal. 2014, 4, 804809, DOI: 10.1021/cs401109u.

(11) Zheng, M.; Cao, X.; Ding, Y.; Tian, T.; Lin, J. Boosting photocatalytic water oxidation achieved by $\mathrm{BiVO}_{4}$ coupled with ironcontaining polyoxometalate: Analysis the true catalyst. J. Catal. 2018, 363, 109-116, DOI: 10.1016/j.jcat.2018.04.022.

(12) Blakemore, J. D.; Crabtree, R. H.; Brudvig, G. W. Molecular Catalysts for Water Oxidation. Chem. Rev. 2015, 115, 12974-13005, DOI: 10.1021/acs.chemrev.5boo122.

(13) Sheehan, S. W.; Thomsen, J. M.; Hintermair, U.; Crabtree, R. H.; Brudvig, G. W.; Schmuttenmaer, C. A. A molecular catalyst for water oxidation that binds to metal oxide surfaces. Nat. Commun. 2015, 6, 6469, DOI: 10.1038/ncomms7469.

(14) Wang, Y.; Li, F.; Zhou, X.; Yu, F.; Du, J.; Bai, L.; Sun, L. Highly Efficient Photoelectrochemical Water Splitting with an Immobilized Molecular $\mathrm{Co}_{4} \mathrm{O}_{4}$ Cubane Catalyst. Angew. Chem. Int. Ed. 2017, 56, 6911-6915, DOI: 10.1002/anie.201703039.

(15) Hunter, B. M.; Gray, H. B.; Müller, A. M. Earth-Abundant Heterogeneous Water Oxidation Catalysts. Chem. Rev. 2016, 116, 14120-14136, DOI: 10.1021/acs.chemrev.6boo398.

(16) Zhong, D. K.; Gamelin, D. R. Photoelectrochemical water oxidation by cobalt catalyst ("Co-Pi")/alpha- $\mathrm{Fe}(2) \mathrm{O}(3)$ composite photoanodes: Oxygen evolution and resolution of a kinetic bottleneck. J. Am. Chem. Soc. 2010, 132, 4202-4207, DOI: 10.1021/jago873oh.

(17) Cummings, C. Y.; Marken, F.; Peter, L. M.; Tahir, A. A.; Wijayantha, K. G. U. Kinetics and mechanism of light-driven oxygen evolution at thin film $\alpha-\mathrm{Fe}_{2} \mathrm{O}_{3}$ electrodes. Chem. Commun. (Camb.) 2012, 48, 2027-2029, DOI: 10.1039/c2cc16382a.

(18) Cen, J.; Wu, Q.; Liu, M.; Orlov, A. Developing new understanding of photoelectrochemical water splitting via in-situ techniques: A review on recent progress. Green Energy Environ. 2017, 2, 100-111, DOI: 10.1016/j.gee.2017.03.001.

(19) Zhang, Y.; Zhang, H.; Liu, A.; Chen, C.; Song, W.; Zhao, J. Rate-Limiting O-O Bond Formation Pathways for Water Oxidation on Hematite Photoanode. J. Am. Chem. Soc. 2018, 140, 32643269, DOI: 10.1021/jacs.7b10979.

(20) Barroso, M.; Cowan, A. J.; Pendlebury, S. R.; Grätzel, M.; Klug, D. R.; Durrant, J. R. The role of cobalt phosphate in enhancing the photocatalytic activity of $\alpha-\mathrm{Fe}_{2} \mathrm{O}_{3}$ toward water oxidation. J. Am. Chem. Soc. 2011, 133, 14868-14871, DOI: 10.1021/ja205325v.

(21) Barroso, M.; Mesa, C. A.; Pendlebury, S. R.; Cowan, A. J.; Hisatomi, T.; Sivula, K.; Grätzel, M.; Klug, D. R.; Durrant, J. R. Dynamics of photogenerated holes in surface modified $\alpha-\mathrm{Fe}_{2} \mathrm{O}_{3}$ photoanodes for solar water splitting. Proc. Natl. Acad. Sci. U. S. A. 2012, 109, 15640-15645, DOI: 10.1073/pnas.1118326109.

(22) Carroll, G. M.; Gamelin, D. R. Kinetic analysis of photoelectrochemical water oxidation by mesostructured $\mathrm{Co}-\mathrm{Pi} / \alpha-\mathrm{Fe} 2$ O 3 photoanodes. J. Mater. Chem. A 2016, 4, 2986-2994, DOI: 10.1039/C5TAo6978E.

(23) Young, K. M. H.; Hamann, T. W. Enhanced photocatalytic water oxidation efficiency with $\mathrm{Ni}(\mathrm{OH})_{2}$ catalysts deposited on $\alpha$ $\mathrm{Fe}_{2} \mathrm{O}_{3}$ via ALD. Chem. Commun. (Camb.) 2o14, 50, 8727-8730, DOI: 10.1039/c4cco2598a.

(24) Lin, F.; Boettcher, S. W. Adaptive semiconductor/electrocatalyst junctions in water-splitting photoanodes. Nat. Mater. 2014, 13, 81-86, DOI: 10.1038/nmat3811. 
(25) Lin, F.; Bachman, B. F.; Boettcher, S. W. Impact of Electrocatalyst Activity and Ion Permeability on Water-Splitting Photoanodes. J. Phys. Chem. Lett. 2015, 6, 2427-2433, DOI: 10.1021/acs.jpclett.5boogo4.

(26) Thorne, J. E.; Jang, J.-W.; Liu, E. Y.; Wang, D. Understanding the origin of photoelectrode performance enhancement by probing surface kinetics. Chem. Sci. 2016, 7, 3347-3354, DOI: 10.1039/C 5 SCo 4519 C.

(27) Thorne, J. E.; Zhao, Y.; He, D.; Fan, S.; Vanka, S.; Mi, Z.; Wang, D. Understanding the role of co-catalysts on silicon photocathodes using intensity modulated photocurrent spectroscopy. Phys. Chem. Chem. Phys. 2017, 351, 29653-29659, DOI: 10.1039/C7CPo6533G.

(28) Zhang, J.; García-Rodríguez, R.; Cameron, P.; Eslava, S. Role of cobalt-iron (oxy)hydroxide ( $\mathrm{CoFeO} \mathrm{x})$ as oxygen evolution catalyst on hematite photoanodes. Energy Environ. Sci. 2018, 11, 2972-2984, DOI: 10.1039/C8EEo1346B.

(29) Klahr, B.; Gimenez, S.; Fabregat-Santiago, F.; Bisquert, J.; Hamann, T. W. Photoelectrochemical and impedance spectroscopic investigation of water oxidation with "Co-Pi"-coated hematite electrodes. J. Am. Chem. Soc. 2012, 134, 16693-16700, DOI: 10.1021/ja3o6427f.

(30) Hajibabaei, H.; Schon, A. R.; Hamann, T. W. Interface Control of Photoelectrochemical Water Oxidation Performance with Ni 1- x Fe x O y Modified Hematite Photoanodes. Chem. Mater. 2017, 29, 6674-6683, DOI: 10.1021/acs.chemmater.7bo1149.

(31) Qiu, J.; Hajibabaei, H.; Nellist, M. R.; Laskowski, F. A. L.; Oener, S. Z.; Hamann, T. W.; Boettcher, S. W. Catalyst Deposition on Photoanodes: The Roles of Intrinsic Catalytic Activity, Catalyst Electrical Conductivity, and Semiconductor Morphology. ACS Energy Lett. 2018, 961-969, DOI: 10.1021/acsenergylett.8boo336.

(32) Pendlebury, S. R.; Wang, X.; Le Formal, F.; Cornuz, M.; Kafizas, A.; Tilley, S. D.; Grätzel, M.; Durrant, J. R. Ultrafast charge carrier recombination and trapping in hematite photoanodes under applied bias. J. Am. Chem. Soc. 2014, 136, 9854-9857, DOI: 10.1021/ja504473e.

(33) Huang, Z.; Lin, Y.; Xiang, X.; Rodríguez-Córdoba, W.; McDonald, K. J.; Hagen, K. S.; Choi, K.-S.; Brunschwig, B. S.; Musaev, D. G.; Hill, C. L. et al. In situ probe of photocarrier dynamics in water-splitting hematite $\left(\alpha-\mathrm{Fe}_{2} \mathrm{O}_{3}\right)$ electrodes. Energy Environ. Sci. 2012, 5, 8923-8926, DOI: 10.1039/c2ee22681b.

(34) Le Formal, F.; Pendlebury, S. R.; Cornuz, M.; Tilley, S. D.; Grätzel, M.; Durrant, J. R. Back electron-hole recombination in hematite photoanodes for water splitting. J. Am. Chem. Soc. 2014, 136, 2564-2574, DOI: 10.1021/ja412058x.

(35) Nellist, M. R.; Laskowski, F. A. L.; Lin, F.; Mills, T. J.; Boettcher, S. W. Semiconductor-Electrocatalyst Interfaces: Theory, Experiment, and Applications in Photoelectrochemical Water Splitting. Acc. Chem. Res. 2016, 49, 733-740, DOI: 10.1021/acs.accounts.6boooo1.

(36) Ma, Y.; Kafizas, A.; Pendlebury, S. R.; Le Formal, F.; Durrant, J. R. Photoinduced Absorption Spectroscopy of CoPi on BiVO 4: The Function of CoPi during Water Oxidation. Adv. Funct. Mater. 2016, 26, 4951-496o, DOI: 10.1002/adfm.201600711.

(37) Cui, C.; Heggen, M.; Zabka, W.-D.; Cui, W.; Osterwalder, J.; Probst, B.; Alberto, R. Atomically dispersed hybrid nickel-iridium sites for photoelectrocatalysis. Nat. Commun. 2017, 8, 634, DOI: 10.1038/s41467-017-01545-w.

(38) Natali, M.; Berardi, S.; Sartorel, A.; Bonchio, M.; Campagna, S.; Scandola, F. Is $\mathrm{Co}_{4}\left(\mathrm{H}_{2} \mathrm{O}\right)_{2}\left(\alpha-\mathrm{PW}_{9} \mathrm{O}_{34}\right)_{2}(10-)$ a genuine molecular catalyst in photochemical water oxidation? Answers from time-resolved hole scavenging experiments. Chem. Commun. (Camb.) 2012, 48, 8808-8810, DOI: 10.1039/c2cc34804g.

(39) Kment, S.; Riboni, F.; Pausova, S.; Wang, L.; Wang, L.; Han, H.; Hubicka, Z.; Krysa, J.; Schmuki, P.; Zboril, R. Photoanodes based on $\mathrm{TiO}_{2}$ and $\alpha-\mathrm{Fe}_{2} \mathrm{O}_{3}$ for solar water splitting - superior role of $\mathrm{i}_{1}$ nanoarchitectures and of combined heterostructures. Chem. Soc. Rev. 2017, 46, 3716-3769, DOI: 10.1039/c6csooo15k.

(40) Wang, D.; Chang, G.; Zhang, Y.; Chao, J.; Yang, J.; Su, S.; Wang, L.; Fan, C.; Wang, L. Hierarchical three-dimensional branched hematite nanorod arrays with enhanced mid-visible light absorption for high-efficiency photoelectrochemical water splitting. Nanoscale 2016, 8, 12697-12701, DOI: 10.1039/c6nro3855g.

(41) Sivula, K.; Zboril, R.; Le Formal, F.; Robert, R.; Weidenkaff, A.; Tucek, J.; Frydrych, J.; Grätzel, M. Photoelectrochemical water splitting with mesoporous hematite prepared by a solution-based colloidal approach. J. Am. Chem. Soc. 2010, 132, 7436-7444, DOI: 10.1021/ja101564f.

(42) Song, F.; Moré, R.; Schilling, M.; Smolentsev, G.; Azzaroli, N.; Fox, T.; Luber, S.; Patzke, G. R. $\left\{\mathrm{Co}_{4} \mathrm{O}_{4}\right\}$ and $\left\{\mathrm{CoxNi}_{4}-\mathrm{xO}_{4}\right\}$ Cubane Water Oxidation Catalysts as Surface Cut-Outs of Cobalt Oxides. J. Am. Chem. Soc. 2017, 139, 14198-14208, DOI: 10.1021/jacs.7bo7361.

(43) Dogutan, D. K.; McGuire, R., JR; Nocera, D. G. Electocatalytic water oxidation by cobalt(III) hangman beta-octafluoro corroles. J. Am. Chem. Soc. 2011, 133, 9178-9180, DOI: 10.1021/ja202138m.

(44) Demeter, E. L.; Hilburg, S. L.; Washburn, N. R.; Collins, T. J.; Kitchin, J. R. Electrocatalytic oxygen evolution with an immobilized TAML activator. J. Am. Chem. Soc. 2014, 136, 5603-56o6, DOI: $10.1021 /$ ja 5015986.

(45) Zhong, D. K.; Cornuz, M.; Sivula, K.; Grätzel, M.; Gamelin, D. R. Photo-assisted electrodeposition of cobalt-phosphate (Co$\mathrm{Pi})$ catalyst on hematite photoanodes for solar water oxidation. Energy Environ. Sci. 2011, 4, 1759-1764, DOI: 10.1039/c1eeo1034d.

(46) Peter, L. M. Dynamic aspects of semiconductor photoelectrochemistry. Chem. Rev. 1990, 90, 753-769, DOI: 10.1021/croo103aoo5.

(47) Klahr, B. M.; Hamann, T. W. Current and Voltage Limiting Processes in Thin Film Hematite Electrodes. J. Phys. Chem. C 2011, 115, 8393-8399, DOI: 10.1021/jp200197d.

(48) Zhang, M.; Frei, H. Water Oxidation Mechanisms of Metal Oxide Catalysts by Vibrational Spectroscopy of Transient Intermediates. Annu. Rev. Phys. Chem. 2017, 68, 209-231, DOI: 10.1146/annurev-physchem-052516-050655.

(49) Iordanova, N.; Dupuis, M.; Rosso, K. M. Charge transport in metal oxides: A theoretical study of hematite alpha-Fe2 $\mathrm{O}_{3} . J$. Chem. Phys. 2005, 122, 144305, DOI: 10.1063/1.1869492.

(5o) Kecsenovity, E.; Endrődi, B.; Tóth, P. S.; Zou, Y.; Dryfe, R. A. W.; Rajeshwar, K.; Janáky, C. Enhanced Photoelectrochemical Performance of Cuprous Oxide/Graphene Nanohybrids. J. Am. Chem. Soc. 2017, 139, 6682-6692, DOI: 10.1021/jacs.7bo182o.

(51) Zhang, Y.; Zhang, H.; Ji, H.; Ma, W.; Chen, C.; Zhao, J. Pivotal Role and Regulation of Proton Transfer in Water Oxidation on Hematite Photoanodes. J. Am. Chem. Soc. 2016, 138, 2705-2711, DOI: 10.1021/jacs.5b12069.

(52) Barroso, M.; Pendlebury, S. R.; Cowan, A. J.; Durrant, J. R. Charge carrier trapping, recombination and transfer in hematite $\left(\alpha-\mathrm{Fe}_{2} \mathrm{O}_{3}\right)$ water splitting photoanodes. Chem. Sci. 2013, 4, 27242734, DOI: 10.1039/c3sc50496d.

(53) Prat, I.; Mathieson, J. S.; Güell, M.; Ribas, X.; Luis, J. M.; Cronin, L.; Costas, M. Observation of $\mathrm{Fe}(\mathrm{V})=\mathrm{O}$ using variabletemperature mass spectrometry and its enzyme-like $\mathrm{C}-\mathrm{H}$ and $\mathrm{C}=\mathrm{C}$ oxidation reactions. Nat. Chem. 2011, 3, 788-793, DOI: 10.1038/nchem.1132.

(54) Zandi, O.; Hamann, T. W. Determination of photoelectrochemical water oxidation intermediates on haematite electrode surfaces using operando infrared spectroscopy. Nat. Chem. 2016, 8, 778-783, DOI: 10.1038/nchem.2557. 
(55) Zhang, M.; Respinis, M. de; Frei, H. Time-resolved observations of water oxidation intermediates on a cobalt oxide nanoparticle catalyst. Nat. Chem. 2014, 6, 362-367, DOI: 10.1038/nchem.1874.

(56) Klahr, B.; Gimenez, S.; Fabregat-Santiago, F.; Hamann, T.; Bisquert, J. Water oxidation at hematite photoelectrodes: The role of surface states. J. Am. Chem. Soc. 2012, 134, 4294-4302, DOI: 10.1021/ja210755h.

(57) Klahr, B.; Gimenez, S.; Fabregat-Santiago, F.; Bisquert, J.; Hamann, T. W. Electrochemical and photoelectrochemical investigation of water oxidation with hematite electrodes. Energy Environ. Sci. 2012, 5, 7626-7636, DOI: 10.1039/c2ee21414h.

(58) Monllor-Satoca, D.; Bärtsch, M.; Fàbrega, C.; Genç, A.; Reinhard, S.; Andreu, T.; Arbiol, J.; Niederberger, M.; Morante, J. R. What do you do, titanium?: Insight into the role of titanium oxide as a water oxidation promoter in hematite-based photoanodes. Energy Environ. Sci. 2015, 8, 3242-3254, DOI: 10.1039/C5EEo1679G.

(59) McDonald, K. J.; Choi, K.-S. Photodeposition of Co-Based Oxygen Evolution Catalysts on $\alpha-\mathrm{Fe}_{2} \mathrm{O}_{3}$ Photoanodes. Chem. Mater. 2011, 23, 1686-1693, DOI: 10.1021/cm1020614.

(6o) Evangelisti, F.; Guttinger, R.; More, R.; Luber, S.; Patzke, G. R. Closer to photosystem II: A $\mathrm{Co}_{4} \mathrm{O}_{4}$ cubane catalyst with flexible ligand architecture. J. Am. Chem. Soc. 2013, 135, 18734-18737, DOI: $10.1021 /$ ja4098302.

(61) Evangelisti, F.; More, R.; Hodel, F.; Luber, S.; Patzke, G. R. 3d-4f $\left\{\mathrm{Co}(\mathrm{II})_{3} \mathrm{Ln}(\mathrm{OR})_{4}\right\}$ Cubanes as Bio-Inspired Water Oxidation Catalysts. J. Am. Chem. Soc. 2015, 137, 11076-11084, DOI: 10.1021/jacs.5bo5831.
(62) Pavliuk, M. V.; Mijangos, E.; Makhankova, V. G.; Kokozay, V. N.; Pullen, S.; Liu, J.; Zhu, J.; Styring, S.; Thapper, A. Homogeneous Cobalt/Vanadium Complexes as Precursors for Functionalized Mixed Oxides in Visible-Light-Driven Water Oxidation. ChemSusChem 2016, 9, 2957-2966, DOI: 10.1002/cssc.201600769.

(63) Duan, L.; Wang, L.; Li, F.; Li, F.; Sun, L. Highly efficient bioinspired molecular Ru water oxidation catalysts with negatively charged backbone ligands. Acc. Chem. Res. 2015, 48, 20842096, DOI: 10.1021/acs.accounts.5boo149.

(64) Karkas, M. D.; Verho, O.; Johnston, E. V.; Akermark, B. Artificial photosynthesis: Molecular systems for catalytic water oxidation. Chem. Rev. 2014, 114, 11863-12001, DOI: 10.1021/cr400572f.

(65) Lin, J.; Liang, X.; Cao, X.; Wei, N.; Ding, Y. An octanuclear $\mathrm{Cu}(\mathrm{ii})$ cluster with a bio-inspired $\mathrm{Cu}_{4} \mathrm{O}_{4}$ cubic fragment for efficient photocatalytic water oxidation. Chem. Commun. (Camb.) 2018, 54, 12515-12518, DOI: 10.1039/c8cco6362a.

(66) Siewert, I.; Gałęzowska, J. Cobalt catalyst with a protonresponsive ligand for water oxidation. Chem. Eur. J. 2015, 21, 27802784, DOI: 10.1002/chem.201405020.

(67) Nestke, S.; Ronge, E.; Siewert, I. Electrochemical water oxidation using a copper complex. Dalton Trans. 2018, 47, 1073710741, DOI: 10.1039/c8dto1323c. 

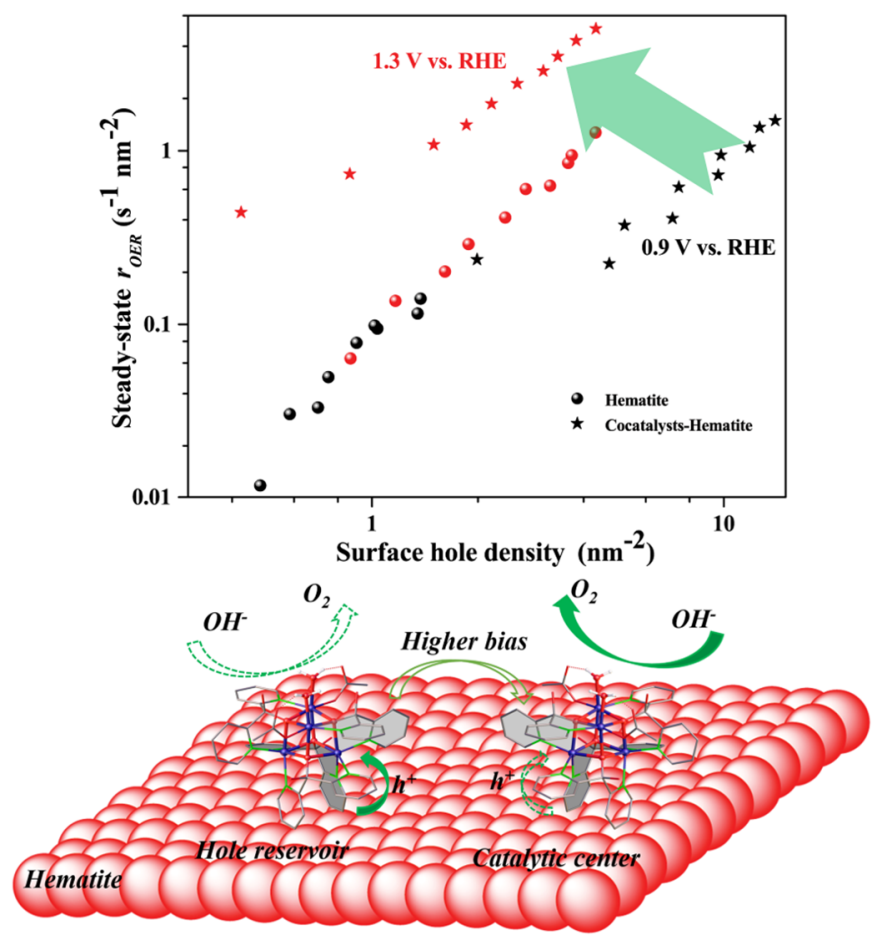